\title{
The relationship between student perceptions of tutor performance and tutors' background in problem-based learning in South Korea
}

\author{
Eun-Kyung Chung1, Maurice A. Hitchcock², Sun-A Oh ${ }^{3}$, Eui-Ryoung Han ${ }^{4}$, Young-Jong Woo' \\ ${ }^{1}$ Department of Medical Education, Chonnam National University Medical School, South Korea \\ ${ }^{2}$ Division of Medical Education, Keck School of Medicine of University Southern California, USA \\ ${ }^{3}$ Center for Biomedical Human Resources, Chonnam National University, South Korea \\ ${ }^{4}$ Office of Education and Research, Chonnam National University Hospital, South Korea
}

Correspondence: Eun-Kyung Chung, Department of Medical Education, Chonnam National University Medical School, Gwangiu, South Korea. E-mail: ekcmedu@chonnam.ac.kr

\begin{abstract}
Objectives: This study was conducted to investigate student perceptions of tutors' group facilitation skills and to evaluate the difference in student perceptions of tutor performance according to the tutors' background in problem based learning (PBL).

Methods: This study used a cross sectional design. One hundred fifty third-year medical students at Chonnam National University Medical School, Gwangju, South Korea were asked to assess their tutors' performance at the end of each PBL tutorial using a self-administered questionnaire. The information collected in the questionnaire addressed tutor performance with regard to constructive/active learning, self-directed learning, contextual learning, collaborative learning, and intrapersonal behavior as a tutor. Tutor background information, such as gender, age, basic or clinical science qualifications, faculty or non-faculty appointment status, and $\mathrm{PBL}$ tutor training program attendance was collected from secondary data provided by
\end{abstract}

the school administration. We performed multiple linear regression analysis using the total student perception score as the dependent variable to compare student perceptions of tutor performance according to the tutors' background.

Results: The mean score for the 11 items on the questionnaire varied between 4.03 and 4.17 on a 5 -point Likert scale. The assessment of student perspectives on tutor performance revealed that students have positive perceptions of tutors' performance in $\mathrm{PBL}$, particularly tutors who were faculty $(\beta=0.255, p=0.035)$ and those who had participated in the PBL tutor-training program $(\beta=0.224, \mathrm{p}=0.046)$.

Conclusions: The study results indicate that exploring how tutors' characteristics influence their performance can be used in planning PBL tutor recruitment and designing PBL tutor-training programs.

Keywords: Problem-based learning, students, perception, faculty, training support

\section{Introduction}

Tutors in problem-based learning (PBL) tutorials have a complex role to play in facilitating students' learning. This includes providing support for students' acquisition of content knowledge and skills in critical thinking, coaching of group processes and modeling of reflective practice. ${ }^{1}$

Because the tutor plays a central role in PBL, the characteristics and skills of effective tutors have received relatively more attention in medical education research. The most common focus of inquiry regarding tutor performance in
PBL has been whether the tutor should be an expert in the content matter related to the problem under study. Research comparing student achievement of tutorial groups guided by either content expert tutors or non-content expert tutors has shown ambiguous results. ${ }^{2-4}$ Studies investigating process differences between content expert and non-content expert tutors have found that content expert tutors tend to use their subject-matter expertise more to direct the discussion in the tutorial group, whereas non- 
content expert tutors use their process-facilitation expertise more to direct the tutorial group. ${ }^{5}$

Studies investigating the related factors to tutor performance have found that a tutor's performance is also dependent on the quality of the cases, structure of PBL courses, link with students' level of prior knowledge, and the functioning of tutorial groups. ${ }^{5}$ Therefore, there may be other factors that contribute to a tutor's influence on student learning in a tutorial setting, and more research is needed about the relation between tutor characteristics and the tutorial group process. Furthermore, there has been a lack of studies exploring the relationship between tutor performance and tutor background in PBL. ${ }^{6}$

Table 1. Tutors' general characteristics $(\mathrm{N}=86)$

\begin{tabular}{lll}
\hline Variable & Classification & No. (\%) \\
\hline Gender & Male & $71(82.6)$ \\
& Female & $15(17.4)$ \\
Age & Under 40 & $40(46.5)$ \\
& Over 40 & $46(53.5)$ \\
Qualification & Basic medical science & $20(23.3)$ \\
& Clinical medicine & $66(76.7)$ \\
Academic appointment & Non-faculty & $14(16.3)$ \\
& Faculty & $72(83.7)$ \\
PBL tutor-training program & Non-attendance & $18(20.9)$ \\
& Attendance & $68(79.1)$ \\
\hline
\end{tabular}

Although tutor performance can be evaluated with selfassessment or by other individuals, such as students, peers, or examiners, desirable tutor skills from a student point of view have received considerable attention. Dolmans et al. reported that students can provide tutors with useful information to improve their performance. ${ }^{7}$ By contrast, Papinczak suggested that, within the PBL tutorial environment at least, regularly evaluating tutors can create mistrust and confusion among the medical school, the tutor and the students on several levels; she recommended enhanced information provision and frank discussion to avoid such problems. ${ }^{8}$ PBL approaches for medical education have been in use in Western countries for more than 40 years, but its use in Asian countries commenced quite recent. Because of cultural differences, the perception of tutor performance from the perspectives of students may be different. ${ }^{9}$

The purpose of this study was to investigate student perceptions of tutors' group facilitation skills and to evaluate the differences in student perceptions of tutor performance according to tutors' background in PBL.

\section{Methods}

\section{The PBL Curriculum and Study Participants}

The PBL program consisted of three, 2-hour sessions per PBL tutorial designed for third-year medical students at Chonnam National University Medical School. Students attended two small-group discussions and a colloquium. Students attended tutorial groups with approximately 10 students, and the discussion focused on the problems. During the discussion, learning issues emerged that required further self study. Between the tutorial meetings, students individually searched for information about these learning issues. In the next tutorial meeting they reported to one another what they found, synthesized the acquired information, and applied it to the problem. In the colloquium, some students gave presentations, and the case writer provided additional information when necessary. One hundred fifty students, divided into 14 small groups, participated in nine PBL tutorials. Eighty-six tutors guided the individual tutorial groups. Each tutor taught an average of 1.5 groups. All tutors were given the opportunity to participate in the study and agreed to be subject to the student evaluations. The tutor characteristics are presented in Table 1. Of the tutors, $71(82.6 \%)$ were male, and 46 (53.5\%) were over 40 years of age. Furthermore, 66 (76.7\%) were clinical physicians, and $72(83.7 \%)$ held academic faculty appointments. Although each tutor was obligated to attend a faculty development seminar focusing on the principles behind problem-based learning and tutoring during the study period, 68 (79.1\%) tutors had already attended these trainings. The Institutional Review Board determined the study exempt from human subjects' research regulations. Consent was obtained from all participants.

Table 2. Participants' response rate in each tutorial $(N=150)$

\begin{tabular}{cc}
\hline & No. (\%) \\
\hline Tutorial 1 & $141(94.0)$ \\
Tutorial 2 & $137(91.3)$ \\
Tutorial 3 & $116(77.3)$ \\
Tutorial 4 & $123(82.0)$ \\
Tutorial 5 & $124(82.7)$ \\
Tutorial 6 & $129(86.0)$ \\
Tutorial 7 & $130(86.7)$ \\
Tutorial 8 & $132(88.0)$ \\
Tutorial 9 & $117(78.0)$ \\
\hline
\end{tabular}

\section{Data Collection}

This study used a cross sectional design. The authors first provided opportunities for students to learn more about tutor evaluation objectives and strategies, and conducted the survey. One hundred fifty third-year medical students were invited to assess their tutors' performance at the end of each of nine PBL tutorials, they were asked to anonymously indicate the degree to which they agreed with each statement on a Likert scale ranging from 1 to $5(1=$ strongly disagree to 5 strongly agree) using a self-administered questionnaire. The number of students participating in each tutorial and their response rate are presented in Table 2. The average response rate was $85.1 \%$. 
The student-centered learning approach of PBL means that for tutors, content knowledge is secondary to proficiency in group facilitation. ${ }^{10}$ Tutors are required to facilitate active learning by students, foster critical thinking skills, and increase a commitment to continued learning. ${ }^{11}$ Thus, this study focused on the evaluation of tutors' group facilitation skills, using the questionnaire developed and validated by Dolmans and Ginns. ${ }^{12}$ Two of the authors who are medical education expert and speak fluent English and Korean translated this questionnaire and verified the accuracy of translation. The questionnaire consists of 11 statements related to tutor performance in containing 4 learning factors and 1 behavior factor: constructive/active learning (3 items), self-directed learning ( 2 items), contextual learning ( 2 items), collaborative learning ( 2 items), and intrapersonal behavior as a tutor ( 2 items). The authors calculated the average scores for the five factors then summed the scores of 11 statements for total students' perception. The Cronbach's alpha reliability coefficient was 0.734 , and the 95\% confidence interval was 0.670, 0.796 .

Background information about the tutor was collected from secondary data provided by the school administration. These data included gender, age, basic or clinical science qualifications, faculty or non-faculty appointment status, and PBL tutor-training program attendance. This information was not revealed to the students, except for the tutor's gender.

\section{Data Analysis}

Mann-Whitney $\mathrm{U}$ tests and Student $t$-tests were used to compare student perceptions of tutor performance according to the tutors' background. We performed multiple linear regression analysis using the total student perception score as the dependent variable. All analyses were performed using SPSS software version 17.0 (SPSS, Inc., Chicago, IL, USA).

\section{Results}

\section{Student perceptions of tutor performance}

Of the five factors measured, the students gave the highest scores to intrapersonal behavior as a tutor and the lowest to stimulating self-directed learning. The mean score for the 11 items varied between 4.03 and 4.17. The highest scoring item was for tutors' knowledge of their strengths and weaknesses. The lowest scoring items were a tutors' ability to stimulate students to understand the underlying mechanism/theories and a tutors' ability to stimulate students to search for various resources (Table 3 ).

\section{Comparison of student perceptions of tutor perfor- mance and background}

Table 4 summarizes the results of the univariate analysis according to the tutors' background.
Mann-Whitney $U$ tests of relevance of academic appointment revealed the faculty tutors had significantly higher scores than did the non-faculty on the contextual and collaborative learning, intrapersonal behavior as a tutor and total students' perception scores. Those who participated in the PBL tutor-training program had significantly higher scores on self-directed learning scale and total students' perception scores. The tutor's gender, age and qualifications were not significantly associated with student perceptions of tutor performance.

The relationship between student perceptions of tutor performance and tutors' background in PBL

The multiple linear regression analysis indicated that the total students' perception score was positively associated with tutors who were faculty $(\beta=0.255, \mathrm{p}=0.035)$ and those who had participated in the PBL tutor-training program $(\beta=0.224, \mathrm{p}=0.046)$. This model was statistically significant $\left(F=2.5, \mathrm{R}^{2}=0.137\right)$ (Table 5).

Table 3. Student perceptions of tutor performance $(\mathrm{N}=86)$

\begin{tabular}{|c|c|c|}
\hline Variable* & Mean & SD \\
\hline F1: Constructive/active learning & 4.06 & .37 \\
\hline \multicolumn{3}{|l|}{ The tutor stimulated students... } \\
\hline 1...to summarize what we had learn in our own words & 4.07 & .37 \\
\hline $\begin{array}{l}\text { 2...to search for links between issues discussed in the } \\
\text { tutorial group }\end{array}$ & 4.07 & .40 \\
\hline 3...to understand underlying mechanism/theories & 4.03 & .39 \\
\hline F2: Self-directed learning & 4.04 & .45 \\
\hline \multicolumn{3}{|l|}{ The tutor stimulated students... } \\
\hline 4 ...to generate clear learning issues by ourselves & 4.05 & .47 \\
\hline 5...to search for various resources by ourselves & 4.03 & .45 \\
\hline F3: Contextual learning & 4.06 & .40 \\
\hline \multicolumn{3}{|l|}{ The tutor stimulated students... } \\
\hline 6...to apply knowledge to the discussed problem & 4.07 & .39 \\
\hline 7...to apply knowledge to other situations/problems & 4.05 & .43 \\
\hline F4: Collaborative learning & 4.06 & .40 \\
\hline \multicolumn{3}{|l|}{ The tutor stimulated students... } \\
\hline 8...to give constructive feedback about our group work & 4.07 & .60 \\
\hline 9...to evaluate group co-operation regularly & 4.08 & .42 \\
\hline F5: Intrapersonal behavior as a tutor & 4.17 & .44 \\
\hline $\begin{array}{l}\text { 10. The tutor had a clear picture about his } \\
\text { strengths/weaknesses }\end{array}$ & 4.17 & .47 \\
\hline $\begin{array}{l}\text { 11. The tutor was clearly motivated to conduct his or her } \\
\text { role }\end{array}$ & 4.16 & .43 \\
\hline Total & 44.89 & 4.27 \\
\hline
\end{tabular}

${ }^{*}$ A 5-point Likert scale

\section{Discussion}

Tutors have an important role in facilitating learning in PBL. ${ }^{13}$ Our study was designed to investigate student perceptions of tutors' group facilitation. The mean score for the 11 facilitation skill items varied between 4.03 and 4.17, as compared to Dolman et al., who found the mean score varied between 3.37 and $4.20 .^{3}$ 
Table 4. Comparison of student perceptions of tutor performance and background $(\mathrm{N}=86)$

\begin{tabular}{|c|c|c|c|c|c|c|c|}
\hline Tutors' variables & Classification & $\begin{array}{c}\mathrm{F}^{\star}{ }^{\star} \\
\text { mean } \pm \mathrm{SD}\end{array}$ & $\begin{array}{c}\mathrm{F} 2^{\star \star} \\
\text { mean } \pm \mathrm{SD}\end{array}$ & $\begin{array}{c}\mathrm{F}^{\dagger} \\
\text { mean } \pm \mathrm{SD}\end{array}$ & $\begin{array}{c}\mathrm{F}^{\ddagger} \\
\text { mean } \pm \mathrm{SD}\end{array}$ & $\begin{array}{c}\mathrm{F5}^{\pi} \\
\text { mean } \pm S D\end{array}$ & $\begin{array}{c}\text { Total } \\
\text { mean } \pm S D\end{array}$ \\
\hline \multirow[t]{3}{*}{ Gender } & Male & $4.04 \pm .38$ & $4.01 \pm .48$ & $4.04 \pm .41$ & $4.03 \pm .45$ & $4.14 \pm .46$ & $44.60 \pm 4.48$ \\
\hline & Female & $4.15 \pm .29$ & $4.16 \pm .26$ & $4.17 \pm .37$ & $4.29 \pm .53$ & $4.27 \pm .31$ & $46.28 \pm 2.80$ \\
\hline & $\mathrm{p}$ value & .453 & .368 & .339 & .131 & .322 & .168 \\
\hline \multirow[t]{3}{*}{ Age } & Under 40 & $4.05 \pm .36$ & $4.04 \pm .42$ & $4.01 \pm .41$ & $4.08 \pm .51$ & $4.17 \pm .36$ & $44.77 \pm 3.98$ \\
\hline & Over 40 & $4.06 \pm .39$ & $4.05 \pm .47$ & $4.11 \pm .39$ & $4.07 \pm .45$ & $4.17 \pm .50$ & $44.99 \pm 4.56$ \\
\hline & $\mathrm{p}$ value & .690 & .640 & .256 & .615 & .438 & .816 \\
\hline \multirow[t]{3}{*}{ Qualification } & Basic medical science & $4.01 \pm .34$ & $3.95 \pm .47$ & $3.99 \pm .38$ & $4.00 \pm .38$ & $4.11 \pm .39$ & $44.40 \pm 4.10$ \\
\hline & Clinical medicine & $4.07 \pm .38$ & $4.07 \pm .44$ & $4.08 \pm .41$ & $4.09 \pm .49$ & $4.18 \pm .46$ & $45.05 \pm 4.35$ \\
\hline & $\mathrm{p}$ value & .744 & .280 & .445 & .339 & .587 & .550 \\
\hline \multirow[t]{3}{*}{ Academic appointment } & Non-faculty & $3.90 \pm .40$ & $3.83 \pm .53$ & $3.81 \pm .38$ & $3.81 \pm .48$ & $3.98 \pm .36$ & $42.57 \pm 4.39$ \\
\hline & Faculty & $4.09 \pm .36$ & $4.09 \pm .42$ & $4.11 \pm .39$ & $4.12 \pm .46$ & $4.21 \pm .45$ & $45.34 \pm 4.13$ \\
\hline & $p$ value & .157 & .099 & .008 & .030 & .022 & .026 \\
\hline \multirow[t]{3}{*}{ PBL tutor -training program } & Non-attendance & $3.94 \pm .37$ & $3.90 \pm .44$ & $3.89 \pm .45$ & $3.91 \pm .54$ & $3.99 \pm .57$ & $43.25 \pm 4.84$ \\
\hline & Attendance & $4.09 \pm .36$ & $4.09 \pm .44$ & $4.11 \pm .38$ & $4.12 \pm .44$ & $4.22 \pm .38$ & $45.42 \pm 3.97$ \\
\hline & $p$ value & .132 & .033 & .053 & .179 & .051 & .042 \\
\hline
\end{tabular}

${ }^{\star}$ Constructive/active learning, ${ }^{\star \star}$ Self-directed learning, ${ }^{\dagger}$ Contextual learning, ${ }^{\ddagger}$ Collaborative learning, ${ }^{\top}$ Intrapersonal behavior as a tutor

In both studies, the lowest scoring items involved how to simulate students to search for resources. An important implication of this finding is that faculty development should place more emphasis on how to guide students in seeking information, prioritizing and planning their approach, making decisions, assessing, interpreting, evaluating, comparing and weighing evidence, and using resources. ${ }^{14}$

The second purpose of this study was to evaluate the relationship between student perceptions of tutor performance and tutors' background in PBL. Students rated tutors who were faculty and those who had participated in the PBL tutor-training program higher than non-faculty and those who had not participated in PBL tutor-training program. Faculty tutors scored significantly higher than non-faculty tutors in three of five factors including self-directed learning, contextual learning, and collaborative learning. Those who had participated in the PBL tutor-training program received significantly higher scores on contextual learning and intrapersonal behavior as a tutor. Baroffio et al. ${ }^{15}$ found that participation in tutor workshops improved participants' understanding of the PBL principles, repertoire of teaching strategies, knowledge of problem content, and ability to guide student learning. Also, Jafri et al. ${ }^{16}$ found that medical residents are an effective supplement to faculty members in facilitating PBL sessions, providing specific education in teaching methods such as facilitation of the
PBL modules and participation in teaching workshops. Our study contributes to the body of research that highlights the importance of faculty development programs that provide training in effective tutoring techniques.

Furthermore, the most common area of inquiry in the domain of desirable PBL tutor characteristics concerns whether a tutor should be an expert in the content matter under study. Silver and Wilkerson ${ }^{17}$ argued that expertise detracts from a tutor's role as a facilitator, in contrast to others, who argue that subject matter experts who have also been trained in facilitation skills are more likely to be the best facilitators. ${ }^{18-19}$ In our study, tutors' qualifications were not significantly associated with students' perception of their performance.

The findings in this study should be interpreted considering the following limitations. First, one of the inherent limitations of educational research using a questionnaire is the role of subjectivity. Second, our study was limited by our focus on the characteristics of successful tutors. A successful tutor may not necessarily be an effective tutor. To evaluate effective teaching by a tutor, student achievement scores and other outcome indicators should be used as a basis for assessment. Third, the small sample size and single institution survey limited the statistical power and affected the statistical significance of the results. Fourth, further research to include other factors that can contribute to tutor performance should be undertaken. 
Table 5. Multiple linear regression analysis using total students' perception score as dependent variable $(\mathrm{N}=86)$

\begin{tabular}{lccc}
\hline & $\begin{array}{c}\text { Regression } \\
\text { coefficient } \\
(\beta)\end{array}$ & $\mathrm{t}$ & $\mathrm{p}$-value \\
\hline Gender & .155 & 1.418 & .160 \\
Age & -.029 & -.238 & .813 \\
Qualification & .142 & 1.264 & .210 \\
Academic appointment & .255 & 2.115 & .038 \\
PBL tutor-training program & .222 & 2.003 & .049 \\
\hline
\end{tabular}

$F=2.530, p=0.035, R^{2}=0.137$, Adjusted $R^{2}=0.083$

Despite the aforementioned limitations, the study findings suggested that students had a positive perception of tutors' performance in PBL, particularly for tutors who were faculty and those who had participated in the PBL tutortraining program. This result can be used in planning PBL tutor recruitment and designing PBL tutor-training programs. Faculty who participated in PBL tutor-training programs must be recruited as a tutor and effective faculty development programs that are tailored to tutors' needs about their ability to guide students' learning (e.g., simulating students to search for resources) should be provided.

\section{Acknowledgments}

This work was supported by a grant of the Chonnam National University in 2007 (2007-0571).

\section{References}

1. Papinczak T, Tunny T, Young L. Conducting the symphony: a qualitative study of facilitation in problembased learning tutorials. Med Educ. 2009;43:377-83.

2. Davis WK, Nairn R, Paine ME, Anderson RM, Oh MS. Effects of expert and non expert facilitators on the smallgroup process and on student performance. Acad Med. 1992;67:470-4.

3. Dolmans DHIM, Wolfhagen IHAP, Schmidt HG. Effects of tutor expertise on student performance in relation to prior knowledge and level of curricular structure. Acad Med. 1996;71:1344-7.

4. Schmidt HG, van der Arend A, Moust JHC, Kokx I, Boon L. Influence of tutors' subject matter expertise on student effort and achievement in problem-based learning Acad Med. 1993;68:784-9.

5. Dolmans DHJM, Gijselaers WH, Moust JHC, de Grave WS, Wolfhagen IHAP, van der Vleuten CPM. Trends in research on the tutor in problem-based learning: conclusions and implications for educational practice and research. Med Teach. 2002;24:173-80.

6. Groves M, Rego P, O'Rourke P. Tutoring in problembased learning medical curricula: the influence of tutor background and style on effectiveness. BMC Med Educ. 2005;5:1-7.

7. Dolmans DHJM, Janssen-Noordman A, Wolfhagen HAP. Can students differentiate between PBL tutors with different tutoring deficiencies? Med Teach. 2006;28:e15661.

8. Papinczak T. An exploration of perceptions of tutor evaluation in problem-based learning tutorials. Med Educ. 2010;44:892-9.

9. Lin CS. Medical students' perception of good PBL tutors in Taiwan. Teach Learn Med. 2005;17:179-83.

10. Barrows HS, Tamblyn RM. Problem-based learning: an approach to medical education. New York: Springer Publishing Co; 1980.

11. Das M, Mpofu DJS, Hasan MY, Stewart TS. Student perceptions of tutor skills in problem-based learning tutorials. Med Educ. 2002;36:272-8.

12. Dolmans DHJM, Ginns P. A short questionnaire to evaluate the effectiveness of tutors in PBL: validity and reliability. Med Teach. 2005;27:534-8.

13. Jung B, Tryssenaar J, Wilkins S. Becoming a tutor: exploring the learning experiences and needs of novice tutors in a PBL programme. Med Teach. 2005;27:606-12.

14. Azer SA. Challenges facing PBL tutors: 12 tips for successful group facilitation. Med Teach. 2005;27:676-81.

15. Baroffio A, Nendaz MR, Perrier A, Layat C, Vermeulen B, VU NV. Effects of teaching context and tutor workshop on tutorial skills. Med Teach. 2006;28:e112-9.

16. Jafri W, Mumtaz K, Burdick WP, Morahan PS, Freeman $\mathrm{R}$, Zehra T. Improving the teaching skills of residents as tutors/facilitators and addressing the shortage of faculty facilitators for PBL modules. BMC Med Educ. 2007;7:1-6.

17. Silver M, Wilkerson L. Effects of tutors with subject expertise on the problem-based tutorial process. Acad Med. 1991;66:298-300.

18. Maudsley G. Roles and responsibilities of the problembased learning tutor in the undergraduate medical curriculum. BMJ. 1999;318:657-61.

19. Neville AJ. The problem-based learning tutor: Teacher? Facilitator? Evaluator? Med Teach. 1999;21:393-401. 